\title{
A piglet with surgically induced exocrine pancreatic insufficiency as an animal model of newborns to study fat digestion
}

\author{
Kateryna Goncharova ${ }^{1,2 *}$, Stefan G. Pierzynowski, ${ }^{1,3 *}$, Danica Grujic ${ }^{4}$, Siarhei Kirko ${ }^{5}$, Katarzyna Szwiec ${ }^{1}$, \\ Jing Wang ${ }^{1}$, Tetiana Kovalenko ${ }^{2}$, Iryna Osadchenko ${ }^{2}$, Galyna Ushakova ${ }^{6}$, Halyna Shmigel ${ }^{7}$, \\ Olexandr Fedkiv ${ }^{8}$, Blanka Majda ${ }^{1}$ and Olena Prykhodko ${ }^{8}$ \\ ${ }^{1}$ Department of Biology, Lund University, Lund, Sweden \\ ${ }^{2}$ Department of Cytology, Bogomoletz Institute of Physiology, Kyiv, Ukraine \\ ${ }^{3}$ Department of Medical Biology, Institute of Rural Health, Lublin, Poland \\ ${ }^{4}$ Alcresta, Newtön, MA, USA \\ ${ }^{5}$ Division of Biochemical Pharmacology, Institute of Pharmacology and Biochemistry, Grodno, Republic of Belarus \\ ${ }^{6}$ Department of Biophysics and Biochemistry, Oles Honchar Dnepropetrovsk National University, Dnepropetrovsk, Ukraine \\ ${ }^{7}$ Department of Biochemistry, Vasyl Stefanyk Prycarpathian National University, Ivano-Frankivsk, Ukraine \\ ${ }^{8}$ SGPlus, Malmö, Sweden
}

(Submitted 23 January 2014 - Final revision received 4 September 2014 - Accepted 12 September 2014 - First published online 28 October 2014)

\section{Abstract}

The maldigestion and malabsorption of fat in infants fed milk formula results due to the minimal production of pancreatic lipase. Thus, to investigate lipid digestion and absorption and mimic the situation in newborns, a young porcine exocrine pancreatic insufficient (EPI) model was adapted and validated in the present study. A total of thirteen EPI pigs, aged 8 weeks old, were randomised into three groups and fed either a milk-based formula or a milk-based formula supplemented with either bacterial or fungal lipase. Digestion and absorption of fat was directly correlated with the addition of lipases as demonstrated by a $30 \%$ increase in the coefficient of fat absorption. In comparison to the control group, a 40 and $25 \%$ reduction in total fat content and 26 and $45 \%$ reduction in $n$-3 and $n$ - 6 fatty acid (FA) content in the stool was observed for lipases 1 and 2, respectively. Improved fat absorption was reflected in the blood levels of lipid parameters. During the experiment, only a very slight gain in body weight was observed in EPI piglets, which can be explained by the absence of pancreatic protease and amylase in the gastrointestinal tract. This is similar to newborn babies that have reduced physiological function of exocrine pancreas. In conclusion, we postulate that the EPI pig model fed with infant formula mimics the growth and lipid digestion and absorption in human neonates and can be used to elucidate further importance of fat and FA in the development and growth of newborns, as well as for testing novel formula compositions.

\section{Key words: Exocrine pancreatic insufficiency: Infant formula: Lipid metabolism: Exogenous lipases}

Nowadays, the majority of infants are nursed using formula when breast-feeding is impossible either due to medical or social reasons ${ }^{(1)}$. The quality of nutrition during the neonatal period has a large impact on the infant's health, cognitive development and overall health status later in life.

Several laboratory animals such as mice, rats, rabbits and guinea pigs have been used as models to study neonatal physiology. However, young pigs have been shown to be most similar to primates, with anatomical, physiological and metabolic features similar to those of human neonates ${ }^{(2-4)}$.
The digestion and absorption of fats provided to the infant via the milk is crucial for the neonate's development in general, but specifically for that of the brain. Long-chain PUFA (LC-PUFA) are important for the appropriate remodelling and growth of cell membranes including myelination within the neonatal brain. Human infants display a naturally low secretion of pancreatic bile salt-dependent lipase (BSDL); however, at the same time, they have an indispensable source of lipase (identical to BSDL), i.e. bile salt-stimulated lipase (BSSL) in their mothers' milk for milk fat digestion ${ }^{(1)}$.

Abbreviations: ARA, arachidonic acid; BSDL, bile salt-dependent lipase; BSSL, bile salt-stimulated lipase; CFA, coefficient of fat absorption; EPI, exocrine pancreatic insufficiency; FA, fatty acid; L1, lipase 1; L2, lipase 2; LC-PUFA, long-chain PUFA; OD, optical density.

*Corresponding authors: K. Goncharova, fax +380 4425624 42, email katerina.goncharova@biol.lu.se; S. G. Pierzynowski, fax +46 4622224206 , email stefan.pierzynowski@biol.lu.se 
In contrast to the human neonate, the pancreas of a newborn pig produces a sufficient amount of BSDL, allowing efficient digestion of milk fat. However, the production of other pancreatic enzymes is low during the neonatal period in both pigs $^{(5)}$ and humans ${ }^{(6)}$.

The young exocrine pancreatic insufficient (EPI) pig model (EPI pigs) has been employed and successfully served in our laboratory as a model for cystic fibrosis ${ }^{(7)}$ and for the absorption of enzymes from the gut ${ }^{(8-10)}$. EPI pigs fed a regular diet exhibit extreme growth retardation compared with their normal growth curve. However, such pigs do not develop cachectic signs in long-term studies and exhibit an insufficient coefficient of fat absorption (CFA) ${ }^{(11-15)}$.

The aim of the present study was to adapt and validate the young EPI pig model to indirectly highlight the role of exogenous lipases in the digestion and subsequent absorption of fat from milk formula in human infants with special emphasis on the absorption of LC-PUFA.

\section{Materials and methods}

All experimental procedures were approved by the University of Lund Ethics Review Committee on Animal Experiments.

\section{Animals}

The experiment was carried out in the research farm of the Department of Agricultural Biosystems and Technology, Swedish University of Agricultural Sciences, Lund, Sweden. A total of thirteen male EPI pigs, aged 7 (SEM 1) weeks and weighing 13 (SEM 2) kg at the start of the experiment, were used in the present study. The pigs were weaned at 4 weeks of age and maintained on a $12 \mathrm{~h}$ day- $12 \mathrm{~h}$ night cycle, with lights on from 06.00 to 18.00 hours. The pigs were individually housed in individual pens (for 3 weeks following surgery) and then in metabolism cages $(140 \mathrm{~cm} \times 90 \mathrm{~cm})$ for the rest of the duration of the experimental period. The individual pens and metabolism cages were both equipped with a feeding trough, drinking nipple and constant heating lamp (150 W). The pigs were allowed to move freely within their pens and metabolism cages, and had visual contact with each other.

\section{Pancreatic duct ligation surgery}

Pancreatic insufficiency was induced by pancreatic duct ligation $^{(8,12)}$. Following surgery, the pigs were allowed a 3 -week recovery period, during which they became accustomed to the conditions of EPI. Development of EPI was confirmed by external symptoms of maldigestion and malabsorption, manifested by growth arrest and the development of steatorrhoea.

\section{Experimental design}

A total of thirteen EPI pigs were randomised into three groups: lipase 1 (L1) group ( $n$ 5) fed with infant formula supplemented with L1; lipase 2 (L2) group ( $n$ 4) fed with infant formula supplemented with L2; control group ( $n$ 4) fed infant formula only. The study included pretreatment, adaptation, control and treatment periods (1 week each). During the pretreatment period, the pigs were fed regular food with consecutive transition within $2 \mathrm{~d}$ to milk formula feeding.

The metabolism cages allowed for the collection of stools, without allowing it to mix with the food. During the adaptation period, the pigs were fed with infant formula alone, without any additives. During the control period, the pigs were fed with infant formula enriched with DHA and arachidonic acid (ARA) as TAG. During the treatment period, the respective groups received milk formulas supplemented with either L1 or L2. Lipases used in the present study were of microbial origin: bacterial (Chromobacterium viscosum) L1 (specific activity $\geq 2500$ units/mg; Sigma) and fungal (Rhizopus oryzae) L2 (specific activity $4019 \cdot 3$ units/mg; Amano). The bacterial and fungal lipases were used to estimate the sensitivity of the model to the lipases of different origins and to highlight their ability to digest LC-PUFA in the gut chyme.

At the end of the treatment period, three consecutive $24 \mathrm{~h}$ collections of faecal samples were made. Each stool sample was immediately removed and kept in the refrigerator. After each $24 \mathrm{~h}$ collection period, stools were homogenised and weighed, and samples for further analyses were stored at $-20^{\circ} \mathrm{C}$.

\section{Feeding and administration of lipases}

Before pancreatic duct ligation surgery, and during the recovery period, the pigs were fed a standard pig diet ('Växtill 320'; Lantmännen) twice daily ( $2 \%$ body mass per meal lasting for $30 \mathrm{~min}$ ). During the adaptation period, the pigs were fed with the cow milk-based formula NAN Pro 1 Gold (Nestlé Sverige), fortified with TAG DHA and TAG ARA from fish oil (NuCheck Prep, Inc.). Formula milk was prepared as a 1:4 dilution of NAN Pro 1 Gold (Nestlé Sverige) in tap water to allow for adequate consumption. The daily formula was divided into four portions, fed during the day starting at 09.00 hours with $3 \mathrm{~h}$ intervals between each feeding. The feeding dose was calculated weekly based on the body weight of the pigs, with a mean of 400-500 g formula powder daily per pig. The concentrations of both TAG ARA and TAG DHA in the formula were $0.22 \mathrm{~g}$ in $100 \mathrm{~g}$ of fat, which is below the recommended levels of $1 \%{ }^{(16)}$. Therefore, in the present study, the formula was enriched with an additional 1\% TAG DHA and 2\% TAG ARA, so that the overall final fat concentration within the diet was approximately $31 \%{ }^{(16,17)}$. Identical daily lipase doses, as measured per unit used, were $30 \mathrm{mg}$ L1 diluted in $1 \mathrm{ml}$ Tris-Cl (pH 7.7) and $250 \mathrm{mg} \mathrm{L} 2$ diluted in $2 \mathrm{ml}$ Tris-Cl ( $\mathrm{pH} 7 \cdot 7$ ), which were equally divided between four meals.

\section{Total fat content measurements}

Fat content was measured in non-processed food samples and faecal samples at a certified laboratory (Eurofins), using a standard gravimetric method (Soxtec System 1043/1046; Tecator AB). The $\mathrm{CFA}^{(7)}$ was calculated according to the following formula:

$$
\begin{aligned}
\% \mathrm{CFA}= & (\text { fat intake }(\mathrm{g} / 24 \mathrm{~h})-\mathrm{fat} \text { in the faeces }(\mathrm{g} / 24 \mathrm{~h})) \\
& \times 100 / \text { fat intake }(\mathrm{g} / 24 \mathrm{~h})
\end{aligned}
$$




\section{Total fatty acid analysis}

For the measurement of LC-PUFA content, faecal samples were analysed using a GC-MS method ${ }^{(18,19)}$. Faecal samples from pigs were lyophilised and homogenised, and total lipids were extracted using chloroform and methanol $(2: 1)^{(18)}$. After $4 \mathrm{~h}$ of incubation at room temperature, samples were filtered and processed for methylation, and fatty acid (FA) methyl esters were prepared ${ }^{(20,21)}$. After transesterification, methyl esters were extracted using three consecutive doses of hexane. After half of the hexane had evaporated in the $\mathrm{N}_{2}$ stream, the samples were loaded onto the GLC (Agilent 6850) and further analysis in the capillary column (30 $\mathrm{m} \times 0.25 \mathrm{~mm}$ inner diameter, $0.25 \mathrm{~mm}$ film thickness, DB-WAX; Agilent) was conducted. The temperature was set as follows: column, $40-195^{\circ} \mathrm{C}$, temperature increased every minute by $6^{\circ} \mathrm{C}$; injector, $230^{\circ} \mathrm{C}$; detector, $230^{\circ} \mathrm{C} . \mathrm{N}_{2}$ was used as a carrier gas. Quantification of FA was done using an internal standard (heptadecanoic acid, 17:0, Sigma-H3500; Sigma-Aldrich)

\section{Blood collection and analysis}

Blood samples were collected from all pigs on the last day of the treatment period in the morning, after a $12 \mathrm{~h}$ overnight fast, via jugular vein puncture. The samples were transferred to tubes coated with lithium heparin (BD Vacutainer ${ }^{\circledR}$, 367884; Becton, Dickinson and Company (BD Medical)) as an anticoagulant, and then centrifuged for $15 \mathrm{~min}$ at $3000 \mathrm{rpm}$. Plasma was removed and the samples were stored at $-20^{\circ} \mathrm{C}$ until further analysis (LC-PUFA, TAG, lipaemic index and NEFA). The effectiveness of the treatment with lipases 1 and 2 on fat absorption was assessed by measuring postprandial changes in blood lipid profiles using the turbidimetry method for the measurement of lipaemic index, and standard chemistry methods for the measurement of NEFA and TAG concentrations.

\section{Lipaemic index}

For the estimation of plasma lipid profile, the method described by Donaldson et al. ${ }^{(22)}$ was used. Volumes of $300 \mu \mathrm{l}$ of fresh plasma samples were loaded into ninety-sixwell microtitre plates in duplicate, and then the turbidity of the samples was measured at two wavelengths (660 and
$700 \mathrm{~nm}$ ) using a Spectramax M2 plate reader (Molecular Devices). Absorbance (optical density, OD) was read using SoftMax Pro 4.6 (Molecular Devices). Lipaemic index was calculated according to the formula below:

Lipaemic index $=\left(\mathrm{OD}_{660 \mathrm{~nm}}-\mathrm{OD}_{700 \mathrm{~nm}}\right) \times 100$.

\section{TAG and NEFA measurements}

Plasma TAG concentrations were analysed at Medilab, Tarnaby, Sweden. NEFA were determined using a standard colorimetric kit (NEFA-C Kit; Wako Chemicals GmbH).

\section{Autopsy}

Pigs were sedated using azaperone $(5 \mathrm{mg} / \mathrm{kg}$, Stresnil; Leo), and euthanised by a single dose of intravenously injected sodium pentobarbiturate $(100 \mathrm{mg} / \mathrm{kg})$. A macroscopic examination was performed with special focus on the pancreatic area, gastrointestinal tract, liver, kidneys and heart.

\section{Histology}

At autopsy, samples from the duodenum and ileum were collected, flushed with ice-cold saline and immediately fixed in Bouin's solution for $48 \mathrm{~h}$. The samples were then dehydrated and embedded into paraffin, according to standard histological techniques. Before routine haematoxylin and eosin (Histolab) staining, tissue blocks were sliced into $5 \mu \mathrm{m}$-thick slices, using a rotor microtome. After staining, samples were dehydrated and mounted under a coverslip with di- $n$-butyl-phthalate in xylene (DPX) medium. Each sample was analysed using a light microscope (Olympus PROVIS).

\section{Statistical analyses}

Data are expressed as means with their standard errors. An ANOVA followed by the Tukey post hoc test or KruskalWallis test was used to assess statistical differences between the groups. All analyses were carried out using Statistica version 7 (StatSoft). $P<0.05$ was considered statistically significant.

Table 1. Mean body weight, formula consumption and stool weight during the treatment period (Mean values with their standard errors)

\begin{tabular}{|c|c|c|c|c|c|c|c|c|}
\hline \multirow[b]{2}{*}{ Items } & \multicolumn{2}{|c|}{ Control (n 4) } & \multicolumn{2}{|c|}{ L1 group (n 5) } & \multicolumn{2}{|c|}{ L2 group (n 4) } & \multicolumn{2}{|c|}{$P$} \\
\hline & Mean & SEM & Mean & SEM & Mean & SEM & L1 v. control & L2 v. control \\
\hline BW (kg) & $15 \cdot 5$ & 0.7 & $16 \cdot 7$ & 1.4 & $14 \cdot 6$ & 1.9 & 0.23 & 0.99 \\
\hline $\mathrm{DFC}^{*}(\mathrm{ml} / 24 \mathrm{~h})$ & $1643 \cdot 0$ & $155 \cdot 5$ & $1890 \cdot 0$ & 31.4 & $1467 \cdot 0$ & $55 \cdot 0$ & 0.63 & 0.96 \\
\hline $\mathrm{SW}^{*}(\mathrm{~g} / 24 \mathrm{~h})$ & $158 \cdot 0$ & $9 \cdot 1$ & 98.0 & 12 & $119 \cdot 0$ & $15 \cdot 3$ & 0.03 & 0.02 \\
\hline
\end{tabular}

L1, lipase 1; L2, lipase 2; BW, body weight; DFC, daily feed consumption; SW, stool weight.

${ }^{*}$ Data presented for DFC and SW are the mean of three consecutive $24 \mathrm{~h}$ collections at the end of the treatment period. 
Table 2. Faecal long-chain PUFA (LC-PUFA) levels in pigs from the control, lipase 1 (L1) and lipase 2 (L2) groups (Mean values with their standard errors)

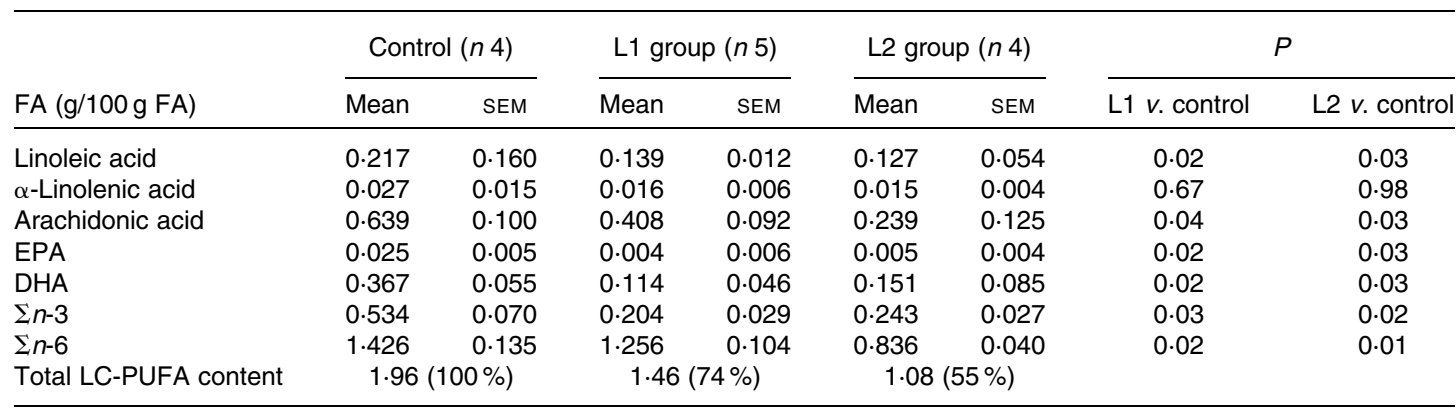

FA, fatty acids.

\section{Results}

\section{Body weight, feed consumption and stool weight}

EPI pigs adapted to the milk formula within 1 week of feeding. During the first few days of milk formula consumption in all groups, slightly loose stools were observed. Elimination of the exocrine pancreas caused growth retardation (average preoperative body weight: 13 (SEM 2) kg; body weight at the end of the experiment (7 weeks later): 14 (SEM 2) kg), and no significant differences between the groups were observed. It should be noted that pigs with an intact pancreas at the age of 15 weeks can weigh between 40 and $50 \mathrm{~kg}$. Supplementation of milk formula both with L1 and L2 for 1 week did not affect growth compared with the control group (Table 1).

Daily feed consumption was equal in all groups (Table 1). After a week of feeding with the milk formula supplemented with lipase enzymes, fat absorption was improved. Visible changes in stool quality were observed (fatty stool disappearance). Average $24 \mathrm{~h}$ stool weight dropped to 60 and $75 \%$ in the groups that were fed the formula supplemented with lipases 1 and 2, respectively, in comparison to the control EPI pigs (Table 1).

Parameters of lipid absorption and intestinal morphology of formula-fed exocrine pancreatic insufficiency pigs

The CFA in EPI pigs fed only the plain milk formula was $59 \cdot 0$ (SEM 5.8) \%, while in pigs reared on the milk-based formula supplemented with either L1 or L2, the CFA was significantly higher for L1 and L2 (84.9 (SEM 4.3) and 85.8 (SEM 3.5)\%, respectively) $(P<0.05)$.

The values of the total fat content in stool, measured as a percentage of daily fat consumption, in the L1 and L2 groups were $49 \cdot 7$ (SEM 4.1) and $51 \cdot 3$ (SEM 5.0) \%, respectively, and were significantly $(P<0.05)$ lower than those observed in the control pigs fed the formula alone (total fat content value: $70 \cdot 8(\operatorname{sem} 7 \cdot 2) \%$ ).

Changes in the stool content of specific $n$-FA (ARA, DHA, EPA, linoleic acid and $\alpha$-linolenic acid) are shown in Table 2. A reduction in stool $n-3$ LC-PUFA of 56 and $54 \%$ compared with that of the control group was observed in groups L1 and L2, respectively. A 12 and $41 \%$ reduction in $n-6$
LC-PUFA was observed in the L1 and L2 groups, respectively, in comparison to the control group. Lipid absorption following the ingestion of a meal in pigs that were fed the milk formula supplemented with lipases is shown in Fig. 1. In the L1 group, a 3-fold increase in lipid absorption was observed $1 \mathrm{~h}$ postprandially, when compared with the control group $(P<0.05)$. In the L2 group, the increase in lipid absorption is approximately 1 -fold $1 \mathrm{~h}$ following ingestion of the meal $(P<0.05)$. No differences in lipaemic index were observed between the groups, $3 \mathrm{~h}$ after a meal.

Postprandial changes in plasma TAG levels are shown in Fig. 2. TAG levels in pigs that received the milk formula supplemented with $\mathrm{L} 1$ increased $1 \mathrm{~h}$ after feeding $(P<0.05)$ and returned to preprandial values $3 \mathrm{~h}$ after feeding. No postprandial changes in plasma TAG levels were observed in the L2 group. Plasma TAG levels in the control group increased significantly $3 \mathrm{~h}$ postprandially.

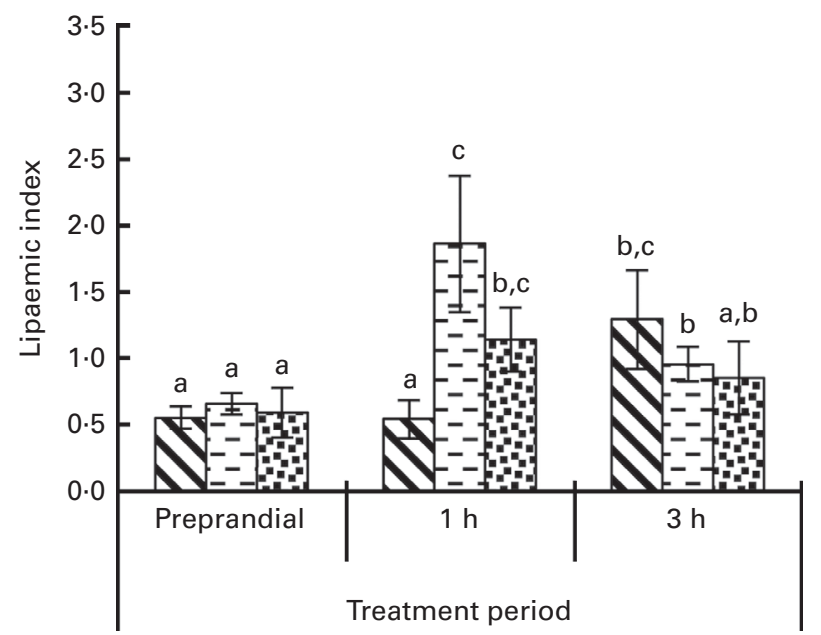

Fig. 1. Changes in lipaemic index from blood samples taken before and after the meal on the last day of the treatment period. Values are means of lipaemic index from blood samples taken $1 \mathrm{~h}$ before the morning meal, $1 \mathrm{~h}$ and $3 \mathrm{~h}$ thereafter, on the last day of the treatment period, for all the three study groups (control $(\nabla)$ group, $n 4$; lipase 1 (L1, 目) group, $n 5$; lipase 2 (L2, 图) group, $n 4$ ), with their standard errors represented by vertical bars. ${ }^{\mathrm{a}, \mathrm{b}, \mathrm{c}}$ Mean values with unlike letters were significantly different between the groups $(P<0.05)$. 


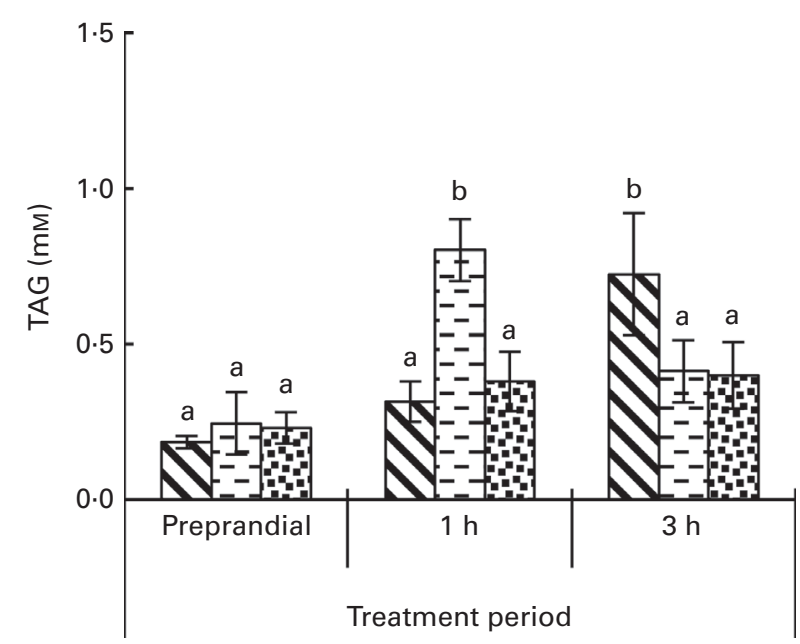

Fig. 2. Changes in TAG concentrations from blood samples taken before and after the meal on the last day of the treatment period. Values are means of TAG concentrations from blood samples taken $1 \mathrm{~h}$ before the morning meal, $1 \mathrm{~h}$ and $3 \mathrm{~h}$ thereafter, on the last day of the treatment period, for all the three study groups (control ( $\nabla$ ) group, $n$ 4; lipase 1 (L1, 目) group, $n$; lipase 2 (L2, 图) group, $n 4)$. ${ }^{\mathrm{a}, \mathrm{b}}$ Mean values with unlike letters were significantly different between the groups $(P<0.05)$.

Preprandial plasma NEFA levels in control pigs were significantly lower $(P<0.05)$ than those observed in the L1 and L2 groups. Plasma levels of NEFA (Fig. 3) dropped significantly $(P<0.05) 1 \mathrm{~h}$ postprandially in the $\mathrm{L} 2$ group and returned to preprandial values $3 \mathrm{~h}$ later. In the $\mathrm{L} 1$ group, plasma NEFA levels remained constant throughout the entire experimental period. In all the groups, postprandial plasma NEFA levels at $3 \mathrm{~h}$ were identical.

Microscopic evaluation of small-intestinal samples showed no evident changes in mucosal structures after consumption of the infant formula enriched with TAG ARA and TAG DHA for 2 weeks. Nevertheless, the villi appeared to be irregular and more finger-like than tongue-like shaped in the ileum, with a high number of goblet cells (Fig. 4). Interestingly, the presence of goblet cells differentiated from the stem cells in the crypt region was abundant compared with other types of newly differentiated cells, observed mainly in the base of the villi for EPI pigs. Moreover, the tissue samples that displayed a higher number of goblet cells were also heavily populated by immune cells, i.e. the ileum and the duodenum (Fig. 4(B), (D), (F) and $(\mathrm{H})$ ). In addition, the tissue from intact pigs of the same age demonstrates an increase in villus height and the number of goblet cells after receiving infant formula for 2 weeks, especially in the ileum (Fig. 4(E) and (F)). Additional tissue examples from an unrelated study were used to show the intestinal morphology of EPI pigs of a similar age, which were fed with regular solid feed (Fig. $4(G)$ and $(H)$ ).

Generally, no obvious changes in small-intestinal mucosal structures were observed between the EPI pigs receiving the plain formula and those receiving the infant formula supplemented with enzymes (Fig. 4(A)-(D)).

\section{Discussion}

In the present study, we aimed to adapt a surgical pig model of EPI that mimics the limited function of the human neonatal pancreas, for investigation of the digestion and absorption of nutrients, specifically fat from infant milk formula. According to various paediatricians, fat absorption in neonates is crucial for their growth and development. Validation of the EPI model was carried out by supplementing exogenous lipases for the digestion of fat within the milk formula, and the parallel measurement of fat absorption by means of the measurements of fat derivatives in the plasma and the fat content of the stools. We hypothesised that young EPI pigs fed a liquid infant milk formula could serve as a model for the investigation of infant nutrition and the consequences of enzyme supplementation of infant formulas on nutrient availability, e.g. lipid digestion, absorption and small-intestinal morphology in non-breast-fed human infants. In the present study, significant improvements in fat absorption as a result of exogenous lipase supplementation validated the sensitivity of the pig model and the different efficacy of the enzymes used. EPI causes the cessation of the secretion of pancreatic enzymes including $\mathrm{BSDL}^{(1-3)}$, and thus mimics the condition of limited pancreatic function in human infants ${ }^{(4)}$. In human neonates, the pancreatic juice contains very small amounts of BSDL, which is identical to BSSL found in the mother's milk, as well as very low levels of other pancreatic enzymes ${ }^{(1,6)}$.

Young pigs were adapted to nursing with a liquid infant milk formula, with essentially different amounts and proportions of nutrients (i.e. regular pig feed for that age group of pigs usually contains only $2-3 \%$ of fat, whereas the milk formula used in the present study contained approximately $30 \%$ fat). No adverse clinical signs associated with the adaptation of pigs to the liquid milk formula diet or pathological post-mortem macroscopic or microscopic findings (along the gut or in the liver) were observed following the $7 \mathrm{~d}$ of

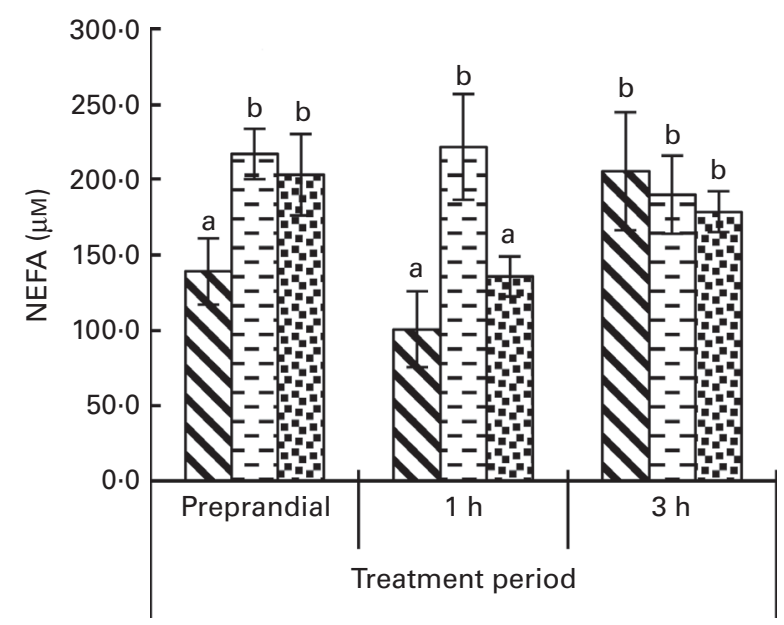

Fig. 3. Changes in NEFA concentrations from blood samples taken before and after the meal on the last day of the treatment period. Values are means of NEFA from blood samples taken $1 \mathrm{~h}$ before the morning meal, $1 \mathrm{~h}$ and $3 \mathrm{~h}$ thereafter, on the last day of the treatment period, for all three study groups (control $(\nabla)$ group, $n$ 4; lipase 1 (L1, 目) group, $n$ 5; lipase 2 (L2, 图) group, $n 4) .{ }^{a, b}$ Mean values with unlike letters were significantly different between the groups $(P<0.05)$. 

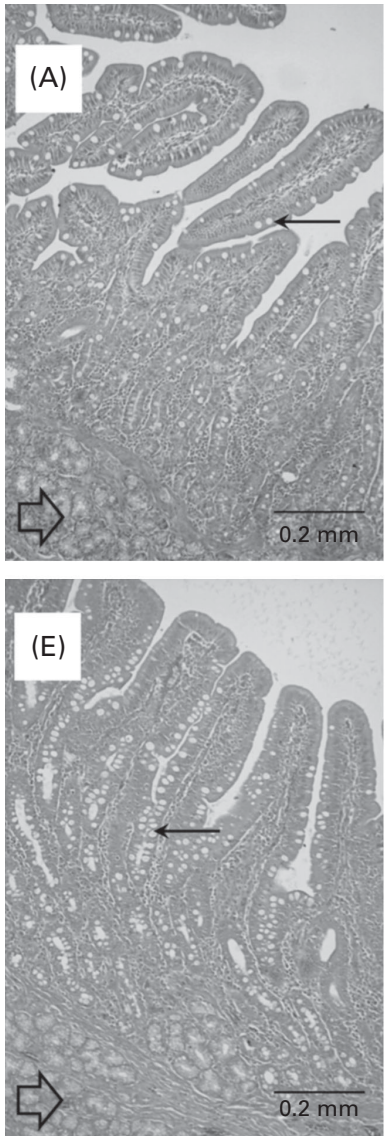
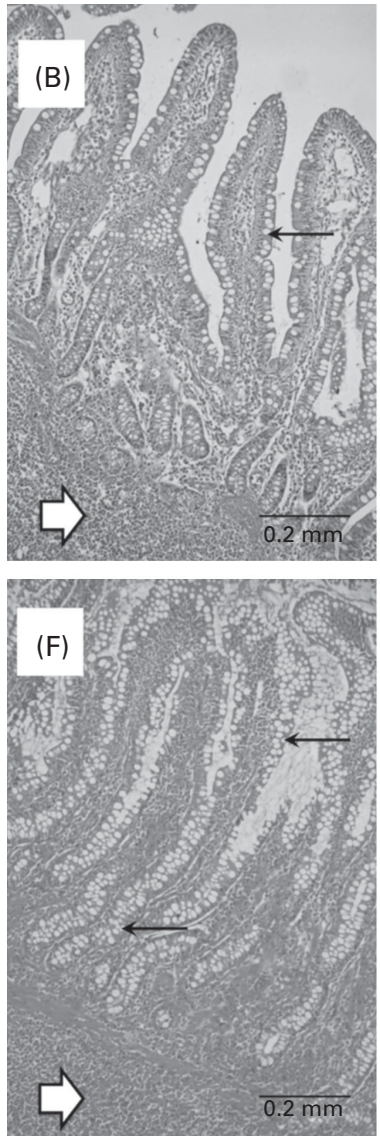
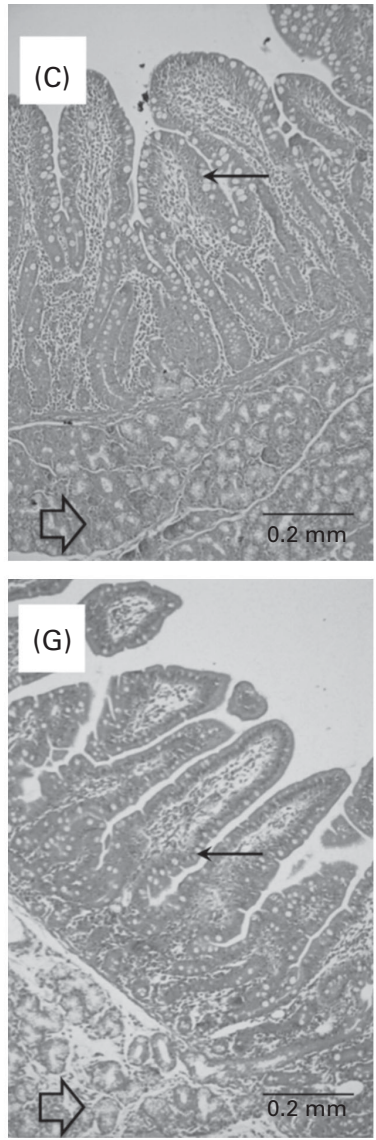
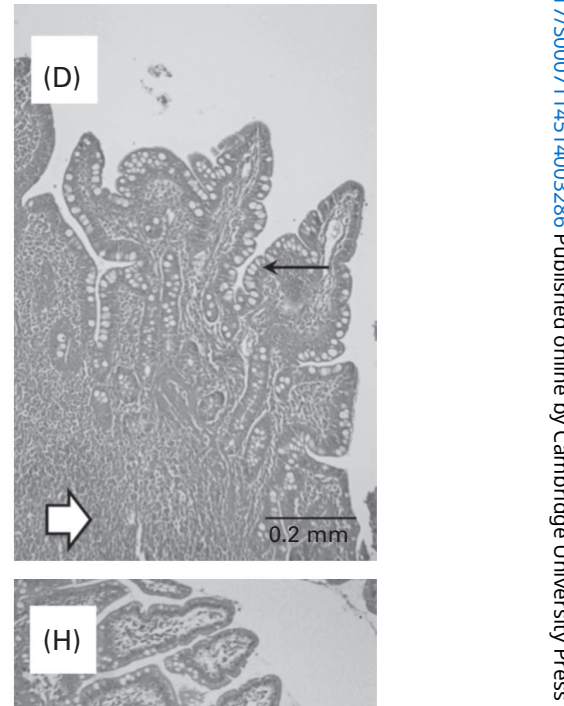

Fig. 4. Photomicrographs of the small-intestinal mucosa of exocrine pancreatic insufficiency (EPI) and healthy pigs after consumption of infant formula for 2 weeks. Haematoxylin and eosin staining of Bouin's fixed, paraffin-embedded samples from (A) the duodenum and (B) ileum of EPI pigs fed with the infant formula, (C) the duodenum and (D) ileum of EPI pigs fed with the formula supplemented with enzymes (lipase 2), (E) the duodenum and (F) ileum of healthy pigs fed with the infant formula, and $(\mathrm{G})$ the duodenum and $(\mathrm{H})$ ileum of EPI pigs fed with the solid food. $\Rightarrow$, Brunners glands; $\Rightarrow$, infiltration of immune cells; $\longleftarrow$, goblet cells. Images E-H were taken from our collection.

enzyme treatment, as well as after the moderately long-lasting period (3 weeks) of milk formula feeding. All pigs adjusted well to the liquid diet during the adaptation period and consumed the milk formula relatively quickly from the jars during the experimental feeding period. EPI pigs fed with the formula that was not supplemented with enzymes developed classical signs of steatorrhoea, which is typical for any EPI condition. In contrast, the EPI pigs fed for $7 \mathrm{~d}$ with the cow milk-based formula supplemented with exogenous lipases and fortified with ARA and DHA did not develop any adverse effects such as diarrhoea, steatorrhoea or vomiting. Thus, we validated the possibility of using the EPI porcine model, adapted to be reared with milk formula, to study the relevance of digestion, but specifically lipid digestion for the human infant. It is well known that fat digestion and absorption in the human infant is essential for their growth and brain development ${ }^{(23,24)}$. Problems with the digestion and absorption of proteins and carbohydrates in human neonates are rare, in comparison to problems associated with the digestion of fat from milk formula, which results from the absence of BSSL normally provided by the mother's milk, as well as from the low secretion of BSDL from the infant pancreas $^{(25)}$. The limited secretion or absence of BSDL secretion in the human infant and in our EPI pig model, respectively, made it extremely valuable to measure the consequences of milk formula supplementation with lipases in terms of the quality of fat absorption. The similarities between human infants and pigs include similar development of the intestine, excluding the closure period that appears during the first $3 \mathrm{~d}$ directly after birth in piglets, and does not exist in humans. Fat digestion and absorption exhibit similar pathways of lipid and lipoprotein metabolism in both pig and human neonates, as well as in full-term human babies, which is why in order to set up an effective model, it is necessary to surgically induce exocrine pancreas insufficiency within the pigs.

Human and pig neonates display similar essential nutrient requirements and natural milk FA composition ${ }^{(26)}$. However, in neonatal pigs, unlike in human babies, the exocrine pancreas is functionally adapted for the efficient digestion of fat components and other nutrients present in the sow's milk ${ }^{(4,5)}$. This is very different from the full-term human newborn that experiences a significant reduction in nutrient digestion and absorption, specifically that of fat. Growth retardation is a consequence of the maldigestion and malabsorption of essential nutrients ${ }^{(11-14)}$. This is exactly what happens during the early stages of the development of 
human neonates. One can speculate that the low pancreatic secretion within the neonate ensures slow/retarded growth, even though the amount of nutrients consumed by the neonates may be sufficient for normal growth. Thus, it can be speculated that growth of human neonates is limited, mostly because of low pancreatic secretion in neonates. This is the reason why the mother's milk plays such an important role in ensuring that lipid digestion takes place by providing BSSL. Therefore, the young EPI pig model with no exocrine pancreatic enzyme secretion perfectly mimics the situation in a human infant with respect to nutritional requirements.

EPI pigs fed the formula supplemented with lipase exhibited improved absorption of $n-3$ and $n-6$ FA measured by the significant reduction of the same FA in the stool samples when compared with the control EPI pigs. Importantly, in the present study, differences in fat hydrolysis between the two tested lipases were observed, suggesting that our EPI pig model is sensitive enough and can be used as a model to test different formula compositions and lipase supplementation necessary for LC-PUFA digestion.

Galeano et $a l^{(27)}$ confirmed that infants fed formula supplemented with PUFA or lipases showed a higher CFA than the non-supplemented group. We observed a similar increase in the CFA in EPI pigs fed with infant formula, supplemented with exogenous lipases. The data from the CFA analysis indicate that the inability of EPI pigs to digest fat was reversed by the supplementation of L1 and L2. The increase in fat absorption in the L1 and L2 groups was also confirmed by the measurement of total fat content in stool. We also observed an increase in the plasma levels of lipaemic index, TAG and NEFA in EPI pigs fed with the cow milk-based formula supplemented with exogenous lipases, reaching values similar to those observed in healthy breast-fed human infants $^{(1)}$.

Histological evidence and earlier observations from our laboratory suggest that the small intestine displays an adaptation to pancreatic duct ligation ${ }^{(28)}$ and to the change in diet from solid food back to a liquid, as seen in intact pigs that did not undergo surgery but were only re-adapted to the milkbased diet. A significant increase in goblet cell numbers due to the EPI condition and/or the infant formula diet might indicate the importance of these cells in the homeostasis of intestinal health. Appearance of some immature-like features such as shape and height of intestinal villi needs to be further investigated, since it could indicate that the intestine of young pigs might be re-adapted back to the previous developmental stage of gut function, e.g. to the suckling period of nourishment.

In conclusion, based on the data obtained from the present study, we can suggest that the model developed can serve as a sensitive tool to test the supplementation of infant formula with exogenous lipases and probably other enzymes. The latter needs to be investigated further in separate studies with milk formula supplemented with enzymes other than lipase.

We are certain that the proposed EPI pig model could be used to elucidate important questions regarding the amount and source of lipase(s) for fat digestion and the consequent absorption and importance of different LC-PUFA for growth and maturation, and finally the effect of nutrients on the development and maturation of the small intestine in breast-fed human infants.

\section{Acknowledgements}

The present study was supported by grants from the Swedish Research Council for Environment, Agricultural Sciences and Spatial Planning (FORMAS grant no. 229-2010-1674), and Anara AB, Malmö, Sweden. FORMAS and Anara AB had no role in the design or analysis of the study and in the writing of this article. Mention of trade names or commercial products in this article is solely for the purpose of providing specific information and does not imply recommendation or endorsement.

The authors' contributions are as follows: K. G., S. G. P. and O. P. were responsible for the preparation of the manuscript; D. G., S. K., K. S., J. W., H. S., O. F., B. M. and K. G. conducted the data analyses of the study; S. G. P., D. G., T. K., I. O., G. U., K. G. were involved in the study performance; S. G. P., D. G., K. G. and O. P. were responsible for the design of the study and the interpretation of the results, as well as critically reviewing the manuscript. All authors approved the final manuscript.

The authors declare that there is no conflict of interest that could be perceived as prejudicing the impartiality of the research reported.

\section{References}

1. Lindquist $S$ \& Hernell $O$ (2010) Lipid digestion and absorption in early life: an update. Opin Clin Nutr Metab Care 13, 314-320.

2. Baker DH (2008) Animal models in nutrition research. J Nutr 138, 391-396.

3. Puiman P \& Stoll B (2008) Animal models to study neonatal nutrition in humans. Curr Opin Clin Nutr Metab Care 11, 601-606.

4. Guilloteau P, Zabielski R, Hammon HM, et al. (2010) Nutritional programming of gastrointestinal tract development. Is the pig a good model for man? Nutr Res Rev $\mathbf{2 3}$, $4-22$.

5. Pierzynowski SG, Weström B, Karlsson B, et al. (1995) Development and regulation of porcine pancreas function - state-of-the-art. Int J Pancreatol 18, 81-94.

6. Zoppi G, Andreotti G, Pajno-Ferrara F, et al. (1972) Exocrine pancreas function in pre-mature and full term neonates. Pediatr Res 96, 880-886.

7. Grujic D, Valverde Piedra JL \& Szymanczyk S, et al. (2010) Liprotamase (lip) - a microbial enzymes preparation reversed impaired growth in pigs model with total exocrine pancreatic insufficiency (EPI). In The American College of Gastroenterology Meeting, San Antonio, CA, USA.

8. Gewert K, Holowachuk SA, Rippe C, et al. (2004) The enzyme levels in blood are not affected by oral administration of a pancreatic enzyme preparation (Creon 10,000) in pancreatic-insufficient pigs. Pancreas 28, 80-88.

9. Huang $M$ (2007) Differential tissues responses of (n-3) and (n-6) PUFA in neonatal piglets fed docosahexaenoate and arachidonate. J Nutr 137, 2049-2055. 
10. Al-Kaade S (2013) Exocrine pancreatic insufficiency. Medscape reference. Drugs, diseases \& procedures. http://emedicine. medscape.com/article/2121028-overview\#showall (accessed December 2013).

11. Saloniemi H, Kalima TV \& Rahko T (1989) Pancreatic enzyme supplementation in normal and exocrine pancreatic insufficient pigs. Acta Vet Scand 30, 367-370.

12. Botermans JA \& Pierzynowski SG (1999) Relations between body weight, feed intake, daily weight gain, and exocrine pancreatic secretion in chronically catheterized growing pigs. J Anim Sci 77, 450-456.

13. Fedkiv O, Rengman S, Westrom BR, et al. (2009) Growth is dependent on the exocrine pancreas function in young weaners but not in growing-finishing pigs. $J$ Physiol Pharmacol 60, Suppl. 3, 55-59.

14. Rengman S, Fedkiv O, Botermans J, et al. (2009) An elemental diet fed, enteral or parenteral, does not support growth in young pigs with exocrine pancreatic insufficiency. Clin Nutr 28, 325-330.

15. Pierzynowski S, Szwiec K, Piedra JLV, et al. (2012) Exogenous pancreatic-like enzymes are recovered in the gut and improve growth of exocrine pancreatic insufficient pigs. J Anim Sci 90, 324-326.

16. Jensen C, Buist NR \& Wilson T (1986) Absorption of individual fatty acids from long chain or medium chain triglyceride in very small infants. Am J Clin Nutr 43, 745-751.

17. Brenna JT, Salem N Jr, Sinclair AJ, et al. (2009) Alpha-linolenic acid supplementation and conversion to $n-3$ long-chain polyunsaturated fatty acids in humans. Prostaglandins Leukot Essent Fatty Acids 80, 85-91.

18. Folch J, Lees M \& Sloane Stanley GH (1957) A simple method for the isolation and purification of total lipides from animal tissues. J Biol Chem 226, 497-509.

19. Moser HW \& Moser AB (1991) Measurement of saturated very long chain fatty acid in plasma. In Techniques in
Diagnostic Human Biomedical Genetics: A Laboratory Manual, pp. 177-191. New York, NY: Wiley-Liss, Inc.

20. Tyburczy C, Kothapalli KS, Park WJ, et al (2011) Heart arachidonic acid is uniquely sensitive to dietary arachidonic and docosahexaenoic acid content in domestic piglets. Prostaglandins Leukot Essent Fatty Acids 85, 335-343

21. Lapillonne A \& Jensen CL (2009) Reevaluation of the DHA requirement for the premature infant. Prostaglandins Leukot Essent Fatty Acids 81, 143-150.

22. Donaldson J, Fed'kiv O, Pawłowska M, et al (2009) The effectiveness of enzymatic replacement therapy measured by turbidimetry and lipaemic index in exocrine pancreatic insufficient young, growing pigs, fed a high-fat diet. $A d v$ Med Sci 54, 7-13.

23. Guyton A \& Hall JE (2006) Textbook of Medical Physiology 11th ed., pp. 808-819. Philadelphia, PA: Elsevier Saunders.

24. Russell FD \& Bürgin-Maunder CS (2012) Distinguishing health benefits of eicosapentaenoic and docosahexaenoic acids. Mar Drugs 10, 2535-2559.

25. Andersson EL, Hernell O, Bläckberg L, et al. (2011) BSSL and PLRP2: key enzymes for lipid digestion in the newborn examined using the Caco-2 cell line. J Lipid Res 52, 1949-1956.

26. Braude R \& Newport MJ (1987) Artificial rearing of pigs. 4 The replacement of butterfat in a whole-milk diet by either beef tallow, coconut oil or soy-bean oil. $\mathrm{Br} J \mathrm{Nutr}$ 29, 447-455.

27. Galeano FN, Darling P, Lepage G, et al. (1987) Taurine supplementation of a premature formula improves fat absorption in preterm infants. Pediatr Res 22, 67-71.

28. Prykhodko O, Fedkiv O, Weström B, et al. (2014) Effects on gut properties in exocrine pancreatic insufficient (EPI) pigs, being growth retarded due to pancreatic duct ligation at 7 weeks but not at 16 weeks of age. Adv Med Sci 59 $74-80$. 